\title{
Substituição Parcial do Farelo de Soja por Soja Integral Extrusada na Dieta de Leitões Desmamados
}

\author{
Teresinha Marisa Bertol'1, Nelson Mores², Márcia Regina Franke ${ }^{3}$
}

\begin{abstract}
RESUMO - Foi desenvolvido um estudo com dois experimentos para avaliação da soja integral extrusada (SIE) como substituta parcial do farelo de soja (FS) na dieta pré-inicial para leitões desmamados aos 21 dias de idade. Em cada experimento foram comparados quatro níveis $(0,20,40$ e $60 \%)$ de substituição do FS pela SIE. A substituição do FS pela SIE no experimento 1 provocou aumento linear do consumo diário de ração (CRD) e da conversão alimentar (CA), sem efeito sobre o ganho de peso diário (GPD) no período total da creche. A altura média da mucosa (AMM) do jejuno inferior reduziu linearmente e a do duodeno apresentou efeito quadrático com o aumento dos níveis de SIE na dieta. No experimento 2, a substituição do FS pela SIE proporcionou efeito quadrático sobre o GPD, o CRD e o peso médio ao final da fase de creche (PM35). Foi concluído que a substituição parcial do farelo de soja pela soja integral extrusada na dieta de leitões desmamados aos 21 dias de idade melhorou o desempenho dos leitões na fase inicial após o desmame. No experimento 1, não foi possível determinar qual o valor máximo de substituição do farelo de soja pela soja integral extrusada, uma vez que houve resposta linear no GPD até o nível de $60 \%$ de substituição. No entanto, no experimento 2, o melhor resultado de ganho de peso, estimado por intermédio da derivação da equação quadrática, foi de $26,82 \%$ de substituição do farelo de soja pela soja integral extrusada, para o período de 0 a 14 dias após o desmame.
\end{abstract}

Palavras-chave: desempenho, diarréia, morfologia intestinal, subprodutos da soja

\section{Partial Substitution of Soybean Meal by Full-Fat Extruded Soybean in Diets for Weaned Piglets}

\begin{abstract}
A study including two experiments was carried out to evaluate partial substitution of soybean meal (SM) by fullfat extruded soybean (ES) in the pre-starter diet, for piglets weaned at 21 days of age. In each experiment four levels $(0,20,40$ and $60 \%)$ of substitution of SM by ES were compared. In the first experiment, daily feed intake (DFI) and feed:gain ratio linearly increased for the total nursery period, due to substitution of SM by ES. Daily gain (DG) was not affected. Average height of the intestinal mucousa (HIM) in the low jejunum was linearly reduced, and in the duodenum had a quadratic effect, when ES was increased. In the experiment 2 , DG, DFI and body weight at the end of the nursery phase (BW35) had a quadratic response, in consequence of substitution of SM by ES. It was concluded that partial substitution of SM by ES in the pre-starter diet for piglets weaned at 21 days of age provide an improvement for performance of piglets in the initial period after weaning. In the experiment 1 , it was not possible to determine the maximum value for substitution of SM by ES, because DG showed a linear response until $60 \%$ of substitution. However, in the experiment 2, the best result for DG, estimated through the derivatization of the quadratic equation, was obtained at $26.82 \%$ of substitution, from 0 to 14 days post weaning.
\end{abstract}

Key Words: diarrhea, intestinal morphology, performance, soybean byproducts

\section{Introdução}

O desenvolvimento do sistema gastrointestinal, em termos de produção e atividade das enzimas digestivas nos leitões após o nascimento, é um processo gradual, que atinge um nível satisfatório aproximadamente na sexta semana de vida. $\mathrm{O}$ alto $\mathrm{pH}$ estomacal nas primeiras semanas prejudica a proteólise péptica das proteínas de origem vegetal (WILSON e LEIBHOLZ, 1981), o que é agravado pela deficiência de produção das enzimas pancreáticas e intestinais, as quais aumentam gradualmente com a idade (LINDEMAN et al., 1986; OWSLEY et al., 1986). Nos primeiros dias após o desmame, ocorre redução da atividade destas enzimas (LINDEMAN et al., 1986; MILLER et al., 1986; McCRACKEN e KELLY, 1993), parcialmente devido às alterações ocorridas na estrutura da parede intestinal, e após alguns dias volta a aumentar até os níveis equivalentes aos de um suíno adulto. Portanto, para desmame aos 21 dias de

\footnotetext{
1 Zoot. M.S., Embrapa Suínos e Aves, Caixa Postal 21, CEP 89700-000, Concórdia - SC. E.mail: tbertol@cnpsa.embrapa.br 2 Med. Vet. M.S., Embrapa Suínos e Aves. E.mail: mores@cnpsa.embrapa.br

${ }^{3}$ Ceval Alimentos, Rod. BR 163, km 6, Zona Rural, CEP 79804-970, Dourados, MS.
} 
idade, a qualidade da dieta fornecida aos leitões imediatamente após o desmame torna-se muito importante, pois é necessário que a mesma seja altamente digestível, com baixa antigenicidade e com alta concentração de nutrientes, devido ao baixo consumo nesta fase. A soja, que é a principal fonte de proteína utilizada nas rações para suínos, contém vários fatores antinutricionais, entre os quais estão os inibidores de tripsina, que limitam o aproveitamento da dieta, e as proteínas antigênicas, as quais causam alterações morfológicas na mucosa intestinal (HANCOCK et al., 1990) e distúrbios digestivos que reduzem o desempenho em leitões jovens (LI et al., 1991b; HANKINS et al., 1992).

O processamento para obtenção do farelo de soja inativa os inibidores da tripsina, porém este produto contém proteínas antigênicas que são absorvidos no sistema digestivo e considerados estranhos pelo sistema humoral sistêmico nos suínos (HANKINS et al., 1992). Em condições ótimas, a extrusão provoca aumento da digestibilidade dos nutrientes (PARTRIDGE e GILL, 1993) e redução da atividade biológica das proteínas antigênicas (FRIESEN et al., 1993). A digestibilidade da matéria seca da soja integral extrusada para leitões na fase de creche é semelhante à do farelo de soja com $44 \%$ de proteína bruta e pouco inferior à do farelo de soja com $46 \%$ de proteína bruta $(86,30$ e $88,41 \%$, respectivamente) (BERTOL e LUDKE, 1999), porém, devido ao seu alto conteúdo de óleo, apresenta altos valores de energia digestível e energia metabolizável, o que facilita a formulação de dietas com altos níveis de energia, necessárias aos leitões após o desmame. O valor de energia metabolizável da soja integral extrusada obtido para leitões entre 35 e 42 dias de idade, de $3819 \mathrm{kcal} / \mathrm{kg}$ (BERTOL e LUDKE, 1999), foi bem inferior ao indicado para suínos adultos.

Este trabalho foi desenvolvido com o objetivo de avaliar a substituição parcial do farelo de soja pela soja integral extrusada em dietas isocalóricas para leitões desmamados aos 21 dias de idade, bem como determinar qual o melhor nível de substituição do farelo de soja por este produto.

\section{Material e Métodos}

\section{Experimento 1}

Foram avaliados quatro níveis (0, 20, 40 e 60\%) de substituição do farelo de soja (FS) pela soja integral extrusada (SIE) na dieta pré-inicial de leitões desmamados aos 21 dias de idade. O experimento foi conduzido nas instalações experimentais do Centro Nacional de Pesquisa de Suínos e Aves, no período de 19 de setembro a 24 de outubro de 1996 . As quatro dietas pré-iniciais foram fornecidas do dia do desmame até 14 dias após. No período seguinte, foi fornecida a mesma dieta inicial a todos os leitões, do $15^{\circ}$ ao $35^{\circ}$ dia após o desmame.

As dietas pré-iniciais (Tabela 1) foram formuladas com os valores de energia metabolizável (EM), obtidos no CNPSA em experimentos de metabolismo com suínos adultos: 3390, 3385 e 4632 kcal para o milho, FS (48\% PB) e SIE, respectivamente.

Os valores nutricionais da SIE e do farelo de soja utilizados estão na Tabela 2. Foi mantido nível constante de óleo de soja entre as dietas, somando-se o óleo presente na SIE e o óleo bruto de soja adicionado. Todas as dietas pré-iniciais continham $14 \%$ de soro de leite em pó e foram mantidas isonutritivas com relação à EM, proteína bruta, cálcio, fósforo disponível, lisina e metionina.

Foram utilizados 128 leitões, com idade média de 21,9 $\pm 0,45$ dias, distribuídos em número de quatro do mesmo sexo por baia, totalizando quatro baias de machos castrados e quatro de fêmeas por tratamento. Os leitões foram distribuídos nos blocos de acordo com o peso inicial e sexo.

No décimo dia do experimento, foi retirado um animal por baia (o mais próximo do peso médio da baia) e abatido para coleta de um fragmento do duodeno (50 $\mathrm{cm}$ posterior ao piloro), dois do jejuno (fragmento 1 a $2 \mathrm{~m}$ e o fragmento 2 a $4 \mathrm{~m}$ posterior ao local de coleta do fragmento do duodeno, respectivamente) e um do íleo (1 m anterior à válvula ileocecal), para medida de altura média da mucosa (AMM). Para avaliação do desempenho e da diarréia, foram considerados os três animais restantes na baia.

Os fragmentos de intestino foram coletados e processados da seguinte forma: foram amarradas as extremidades de cerca de cinco $\mathrm{cm}$ de cada porção do intestino e introduzido $10 \mathrm{ml}$ do fixador (formalina $10 \%$ tamponada) no lúmem de cada fragmento. Em seguida, os fragmentos foram separados do restante do intestino e submergidos no mesmo fixador por 48 horas. Posteriormente, foram processados fragmentos transversais com cerca de $2 \mathrm{~mm}$ e, pelo método de inclusão em parafina, foram feitas três lâminas de cada fragmento em micrótomo rotativo, com 5 micras de espessura, as quais foram coradas pelo método da hematoxilina-eosina (LUNA, 1968) e examinadas em microscópio óptico. A altura da mucosa (distância entre a túnica muscular da submucosa até o topo de 
Rev. bras. zootec.

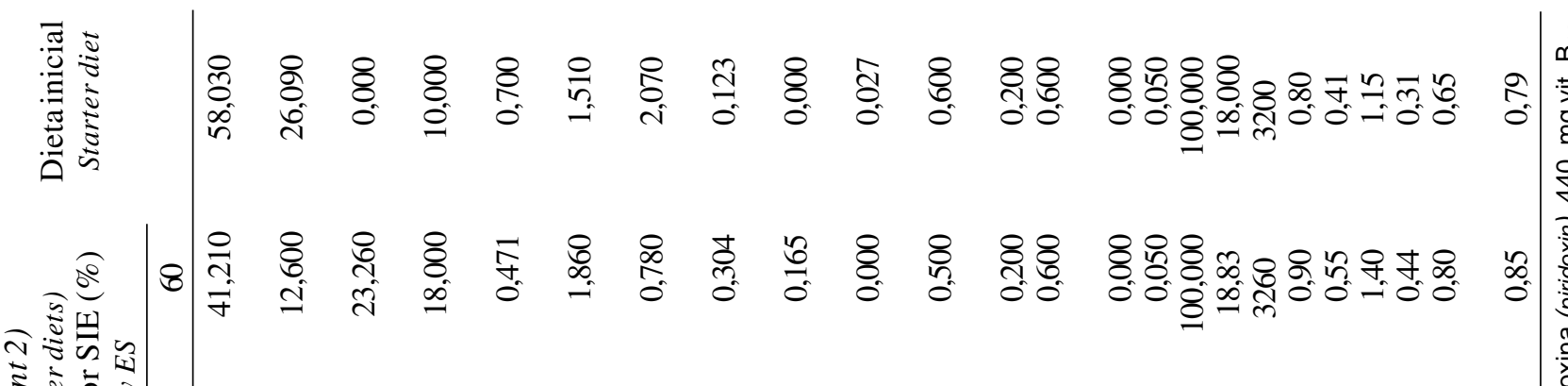

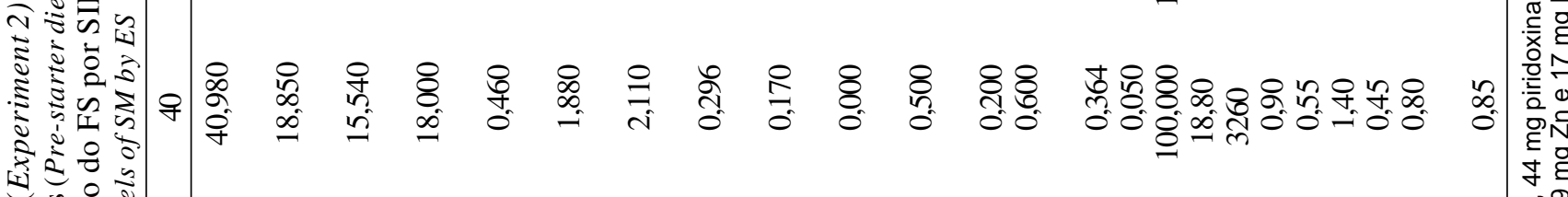

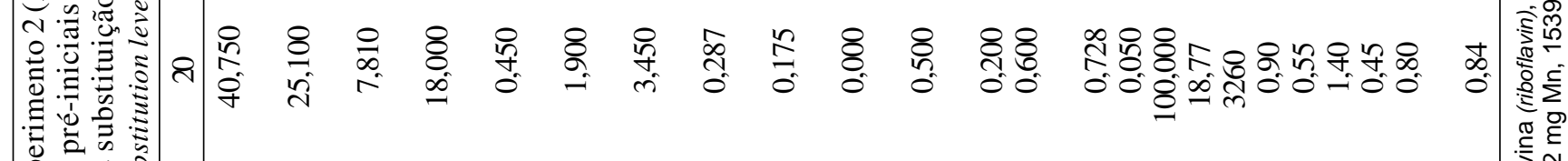

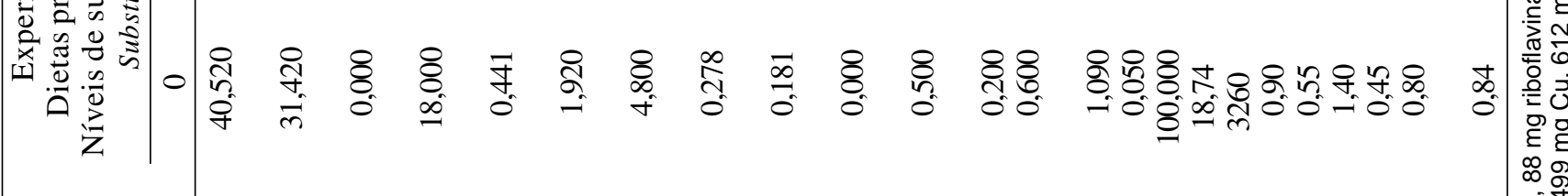

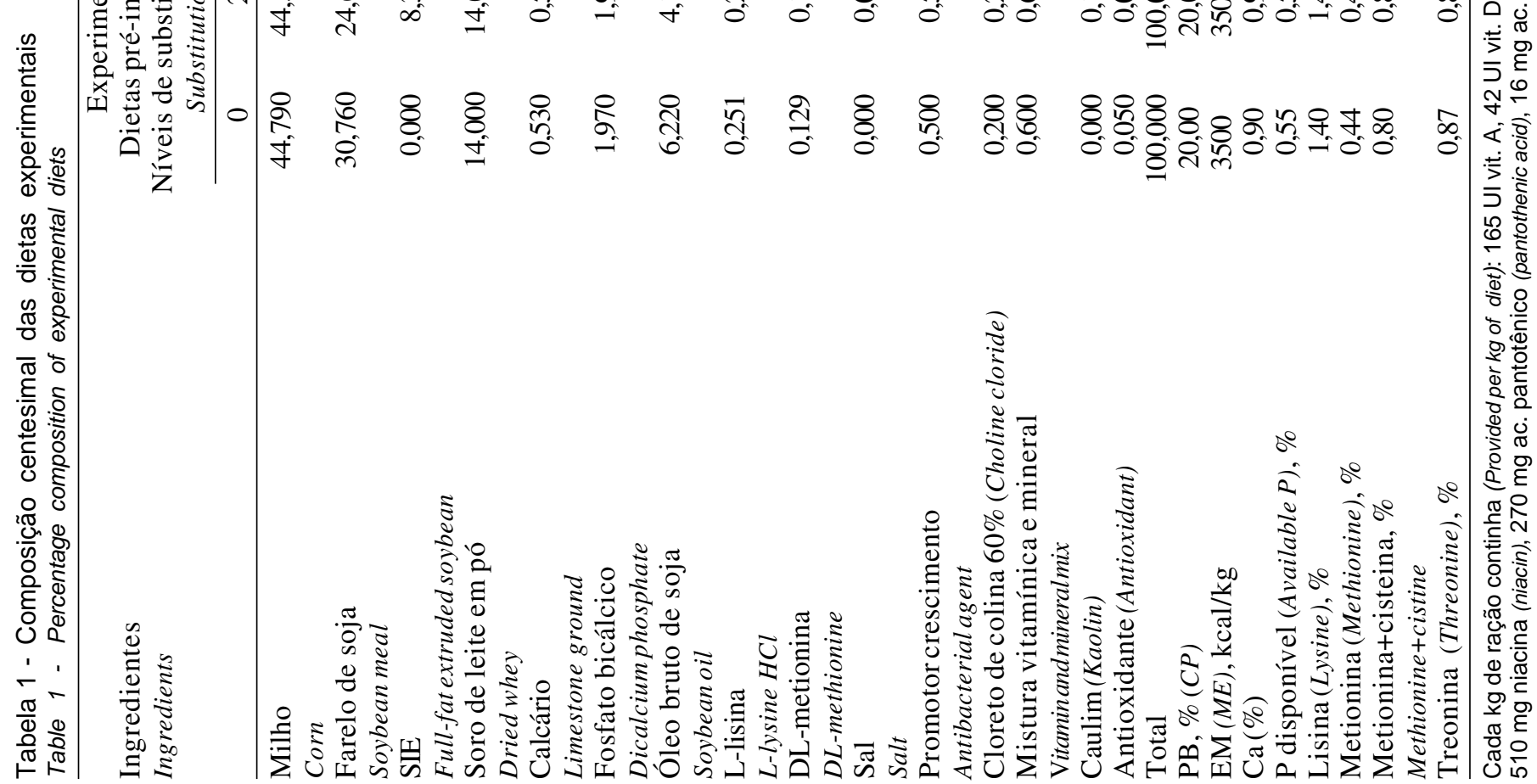


vilosidades integras e bem orientadas) foi medida em três pontos de cada lâmina, totalizando nove medidas em cada fragmento. As medidas foram feitas usando-se microscópio óptico Carl Zeiss Jena (Jeneval), com objetiva $3,2 \mathrm{X}$, equipada com retículo (régua) previamente calibrado para medidas em micras. Foram feitas as médias das nove leituras de cada fragmento, as quais foram utilizadas para análise estatística.

\section{Experimento 2}

Foram avaliados quatro níveis (0, 20, 40 e 60\%) de substituição do FS pela SIE na dieta pré-inicial de leitões desmamados aos 21 dias de idade. O experimento foi conduzido nas instalações experimentais do Centro Nacional de Pesquisa de Suínos e Aves, no período de 09 de janeiro a 27 de fevereiro de 1997 . As quatro dietas pré-iniciais foram fornecidas do dia do desmame até 14 dias após. No período seguinte foi fornecida a mesma dieta inicial a todos os leitões, do $15^{\circ}$ ao $35^{\circ}$ dia após o desmame.

De forma a se obter uma avaliação mais concreta das diferenças entre FS e SIE, as dietas pré-iniciais deste experimento (Tabela 1) foram formuladas com base nos resultados de EM obtidos para leitões de 28 dias de idade por BERTOL e LUDKE (1999) para o milho, FS (44\% PB), SIE e soro de leite em pó, os quais foram de 3292, 3099, 3819 e $3112 \mathrm{kcal} / \mathrm{kg}$, respectivamente. Para o óleo bruto de soja foi utilizado valor de tabela (EMBRAPA, 1991). Os valores nutricionais da SIE e do farelo de soja utilizados neste experimento estão na Tabela 2. Foi mantido nível constante de óleo de soja entre as dietas, somando-se o óleo presente na SIE e o óleo bruto de soja adicionado. Todas as dietas pré-iniciais continham $18 \%$ de soro de leite em pó e foram mantidas isonutritivas com relação à EM, lisina, metionina cálcio e fósforo disponível.

O experimento foi instalado em dois grupos com diferença de 14 dias entre um e outro. Foram utilizados 96 leitões, com idade média de 20,6 \pm 1,32 dias no grupo 1 e 20,9 $\pm 1,11$ no grupo 2 , distribuídos em número de três do mesmo sexo por baia, totalizando quatro baias de macho e quatro de fêmea por tratamento. Em cada grupo, os leitões foram distribuídos em blocos de acordo com o peso inicial e sexo.

Além da avaliação de desempenho, nos dois experimentos foi feita também avaliação diária da incidência de diarréia nos primeiros 14 dias após o desmame, através do seguinte escore: 0 - fezes normais, 1 - fezes pastosas, 2 - fezes entre líquidas e pastosas e 3 - fezes líquidas.

Os dados de desempenho e AMM dos dois experimentos foram submetidos à análise de regressão
Tabela 2 - Composição nutricional da soja integral extrusada (SIE) e do farelo de soja (FS) utilizados nos experimentos 1 (FS1) e 2 (FS2)

Table 2 - Nutritional composition of full-fat extruded soybean (ES) and soybean meal (SM) used in the experiments 1 (SM1) and 2 (SM2)

\begin{tabular}{|c|c|c|c|}
\hline $\begin{array}{l}\text { Nutrientes, \% } \\
\text { Nutrients }\end{array}$ & $\begin{array}{l}\text { SIE } \\
E S\end{array}$ & $\begin{array}{c}\text { FS1 } \\
\text { SM }\end{array}$ & $\begin{array}{c}\mathrm{FS} 2 \\
S M\end{array}$ \\
\hline $\begin{array}{l}\mathrm{EM}, \mathrm{kcal} / \mathrm{kg} \\
M F\end{array}$ & $* *$ & 3385 & 3099 \\
\hline $\begin{array}{l}\text { Proteína bruta } \\
\text { Crude protein }\end{array}$ & 35,86 & 48,31 & 44,17 \\
\hline $\begin{array}{l}\text { Lisina } \\
\text { Lysine }\end{array}$ & 2,25 & 3,12 & 2,90 \\
\hline $\begin{array}{l}\text { Metionina } \\
\text { Methionine }\end{array}$ & 0,46 & 0,69 & 0,52 \\
\hline $\begin{array}{l}\text { Metionina+cistina } \\
\text { Methionine+cistine }\end{array}$ & 1,01 & 1,38 & 1,18 \\
\hline $\begin{array}{l}\text { Triptofano } \\
\text { Tryptophan }\end{array}$ & 0,54 & 0,69 & 0,64 \\
\hline $\begin{array}{l}\text { Treonina } \\
\text { Threonine }\end{array}$ & 1,42 & 1,90 & 1,70 \\
\hline $\begin{array}{l}\text { Histidina } \\
\text { Histidine }\end{array}$ & 0,87 & 1,20 & 1,12 \\
\hline $\begin{array}{l}\text { Isoleucina } \\
\text { Isoleucine }\end{array}$ & 1,60 & 2,13 & 2,00 \\
\hline $\begin{array}{l}\text { Leucina } \\
\text { Leucine }\end{array}$ & 2,64 & 3,63 & 3,37 \\
\hline $\begin{array}{l}\text { Fenilalanina+tirosina } \\
\text { Phenylalanine }+ \text { tyrosine }\end{array}$ & 3,06 & 4,07 & 3,60 \\
\hline $\begin{array}{l}\text { Valina } \\
\text { Valine }\end{array}$ & 1,62 & 2,47 & 2,02 \\
\hline
\end{tabular}

** Foram atribuídos valores de 4632 e $3819 \mathrm{kcal} / \mathrm{kg}$ para a SIE nos experimentos 1 e 2 , respectivamente.

** It was assumed values of 4632 and $3819 \mathrm{kcal} / \mathrm{kg}$ to ES in the experiments 1 and 2, respectively.

polinomial; os valores máximos para GPD foram estimados por meio da derivação das equações quadráticas para os períodos de 0 a 14 e 15 a 35 dias de experimento e os dados de diarréia foram submetidos à análise de qui-quadrado de Pearson (SAS, 1996).

\section{Resultados e Discussão}

\section{Experimento 1}

A substituição do FS pela SIE provocou aumento linear no ganho de peso diário (GDP; $\mathrm{P}<0,03$, $\mathrm{y}=92+0,81 \mathrm{x}$ ), no consumo diário de alimento (CRD; $\mathrm{P}<0,002, \mathrm{y}=220+0,96 \mathrm{x})$ e no peso médio aos 14 dias (PM14, $\mathrm{P}<0,08 ; \mathrm{y}=9,60+0,012 \mathrm{x}$ ) e redução linear da conversão alimentar (CA; $\mathrm{P}<0,06, \mathrm{y}=2,61-0,050 \mathrm{x})$, no período de 0 a 14 dias após o desmame (Tabela 3 ).

No período de 15 a 35 dias após o desmame, o GPD e o CRD foram semelhantes entre os tratamentos, 
748 Rev. bras. zootec.

não havendo efeito residual das dietas fornecidas no período anterior. Porém, a CA piorou de modo linear $(\mathrm{P}<0,06, \mathrm{y}=1,56+0,0016 \mathrm{x})$ com o aumento dos níveis de SIE na dieta da fase anterior. No período total (0 a 35 dias), foi observado aumento linear do CRD $(\mathrm{P}<0,08 ; \mathrm{y}=667+0,94 \mathrm{x})$ e da $\mathrm{CA}(\mathrm{P}<0,06$; $y=1,63+0,001 x)$, sem efeito $(P>0,05)$ sobre o ganho diário de peso.

Não houve efeito dos tratamentos $(\mathrm{P}>0,05)$ sobre o número de leitões que apresentaram diarréia (NLD), bem como sobre o número de dias com diarréia (NLDD, Tabelas 4 e 5). Houve morte de um leitão do nível 20\% na primeira fase do experimento e um do nível $40 \%$ na segunda fase, ambos em conseqüência de doença do edema. Entre os leitões abatidos para coleta de amostra do intestino, os do nível $0 \%$ de substituição do FS foram os que apresentaram a maior incidência de diarréia e com a maior duração (Tabela 6, dados não analisados).

A AMM do duodeno apresentou efeito quadrático $(\mathrm{P}<0,05)$ dos tratamentos, com o maior valor para o nível $0 \%$ de substituição do FS. No fragmento 2 coletado no jejuno, a AMM reduziu linearmente $(\mathrm{P}<0,01)$ com o aumento dos níveis de SIE na dieta, enquanto no fragmento 1 do jejuno e no íleo não houve efeito significativo dos tratamentos para esta variável (Tabela 7).

Neste experimento, a melhora obtida no GPD nos tratamentos com os níveis mais altos de SIE, até 14

Tabela 3 - Efeito da substituição parcial do farelo de soja (FS) por soja integral extrusada (SIE) sobre o desempenho de leitões desmamados aos 21 dias de idade (experimento 1)

Table 3 - Effect of partial substitution of soybean meal (SM) by full-fat extruded soybean (ES) on the performance of piglets weaned at 21 days of age (experiment 1)

\begin{tabular}{|c|c|c|c|c|}
\hline & \multicolumn{4}{|c|}{$\begin{array}{l}\text { Níveis de substituição do FS por SIE (\%) } \\
\text { Substitution levels of SM by ES }\end{array}$} \\
\hline & 0 & 20 & 40 & 60 \\
\hline & \multicolumn{4}{|c|}{$\begin{array}{l}0 \text { a } 14 \text { dias } \\
0 \text { to } 14 \text { days }\end{array}$} \\
\hline $\begin{array}{l}\text { Peso médio inicial, } \mathrm{kg} \\
\text { Initial mean weight, } \mathrm{kg}\end{array}$ & $8,19 \pm 1,05$ & $8,27 \pm 0,84$ & $8,27 \pm 0,69$ & $8,23 \pm 0,84$ \\
\hline $\begin{array}{l}\text { Ganho peso diário }{ }^{1}, \mathrm{~g} \\
\text { Daily weight gain }{ }^{1}, g\end{array}$ & $92 \pm 40$ & $101 \pm 44$ & $131 \pm 34$ & $134 \pm 30$ \\
\hline $\begin{array}{l}\text { Consumo ração diário }{ }^{2}, \mathrm{~g} \\
\text { Daily feed intake }{ }^{2}, g\end{array}$ & $217 \pm 40$ & $239 \pm 35$ & $262 \pm 31$ & $277 \pm 26$ \\
\hline $\begin{array}{l}\text { Conversão alimentar } \\
\text { Feed:gain ratio }\end{array}$ & $2,65 \pm 0,75$ & $2,70 \pm 0,92$ & $1,92 \pm 0,47$ & $2,19 \pm 0,48$ \\
\hline \multirow[t]{2}{*}{$\begin{array}{l}\text { Peso médio aos } 14 \text { dias }^{4}, \mathrm{~kg} \\
\text { Average weight at } 14 \text { days }^{4}, \mathrm{~kg}\end{array}$} & $9,58 \pm 1,23$ & $9,68 \pm 1,34$ & $10,10 \pm 0,73$ & $10,18 \pm 0,86$ \\
\hline & \multicolumn{4}{|c|}{$\begin{array}{l}15 \text { a } 35 \text { dias } \\
15 \text { to } 35 \text { days }\end{array}$} \\
\hline $\begin{array}{l}\text { Ganho peso diário, } \mathrm{g} \\
\text { Daily weight gain, } g\end{array}$ & $615 \pm 48$ & $629 \pm 26$ & $602 \pm 70$ & $616 \pm 75$ \\
\hline $\begin{array}{l}\text { Consumo ração diário, } \mathrm{g} \\
\text { Daily feed intake, } g\end{array}$ & $967 \pm 70$ & $988 \pm 58$ & $979 \pm 105$ & $1024 \pm 137$ \\
\hline $\begin{array}{l}\text { Conversão alimentar } \\
\text { Feed:gain ratio }\end{array}$ & $1,57 \pm 0,03$ & $1,57 \pm 0,08$ & $1,63 \pm 0,11$ & $1,67 \pm 0,14$ \\
\hline \multirow[t]{2}{*}{$\begin{array}{l}\text { Peso médio aos } 28 \text { dias, } \mathrm{kg} \\
\text { Average weight at } 28 \text { days, } \mathrm{kg}\end{array}$} & $17,23 \pm 1,61$ & $17,71 \pm 1,73$ & $18,00 \pm 1,28$ & $17,88 \pm 1,84$ \\
\hline & \multicolumn{4}{|c|}{$\begin{array}{l}0 \text { a } 35 \text { dias } \\
0 \text { to } 35 \text { days }\end{array}$} \\
\hline $\begin{array}{l}\text { Ganho peso diário, } \mathrm{g} \\
\text { Daily weight gain, } g\end{array}$ & $406 \pm 33$ & $418 \pm 25$ & $417 \pm 46$ & $423 \pm 52$ \\
\hline $\begin{array}{l}\text { Consumo ração diário }{ }^{4}, \mathrm{~g} \\
\text { Daily feed intake } e^{4}, g\end{array}$ & $667 \pm 42$ & $689 \pm 47$ & $692 \pm 73$ & $725 \pm 84$ \\
\hline $\begin{array}{l}\text { Conversão alimentar } \\
\text { Feed: } \text { gain ratio }^{3}\end{array}$ & $1,65 \pm 0,05$ & $1,65 \pm 0,04$ & $1,66 \pm 0,06$ & $1,72 \pm 0,11$ \\
\hline $\begin{array}{l}\text { Peso médio aos } 35 \text { dias, } \mathrm{kg} \\
\text { Average weight at } 35 \text { days, } \mathrm{kg}\end{array}$ & $22,48 \pm 1,93$ & $22,89 \pm 1,71$ & $22,92 \pm 1,91$ & $23,11 \pm 2,16$ \\
\hline
\end{tabular}

1 Efeito linear $(P<0,03),{ }^{2}$ Efeito linear $(P<0,002),{ }^{3}$ Efeito linear $(P<0,06),{ }^{4}$ Efeito linear $(P<0,08)$.

1 Linear response $(P<.03),{ }^{2}$ Linear response $(P<.002),{ }^{3}$ Linear response $(P<.06),{ }^{4}$ Linear response $(P<.08)$. 
BERTOL et al.

Tabela 4 - Efeito dos níveis de substituição do farelo de soja (FS) da dieta por soja integral extrusada (SIE) sobre o número total de leitões que apresentaram diarréia durante os primeiros 14 dias após o desmame (experimentos 1 e 2)

Table 4 - Effect of partial substitution of soybean meal (SM) by full-fat extruded soybean (ES) on the number of piglets whith diarrhea during the first 14 postweaning days (experiments 1 and 2)

\begin{tabular}{|c|c|c|c|c|}
\hline \multirow{2}{*}{$\begin{array}{l}\text { Níveis de substituição } \\
\text { do FS por SIE, \% } \\
\text { Substitution levels } \\
\text { of SM by ES, \% }\end{array}$} & \multicolumn{2}{|c|}{$\begin{array}{l}\text { Experimento } 1 \\
\text { Experiment } 1\end{array}$} & \multicolumn{2}{|c|}{$\begin{array}{c}\text { Experimento } 2 \\
\text { Experiment } 2\end{array}$} \\
\hline & $\begin{array}{c}\text { № total leitões } \\
\text { Total number } \\
\text { of piglets }\end{array}$ & $\begin{array}{c}\text { № leitões com diarréia } \\
\text { Number of piglets } \\
\text { with diarrhea }\end{array}$ & $\begin{array}{c}\text { № total leitões } \\
\text { Total number } \\
\text { of piglets }\end{array}$ & $\begin{array}{c}\text { № leitões com diarréia } \\
\text { Number of piglets } \\
\text { with diarrhea }\end{array}$ \\
\hline 0 & 24 & 14 & 24 & 13 \\
\hline 20 & 24 & 14 & 24 & 11 \\
\hline 40 & 24 & 13 & 24 & 13 \\
\hline 60 & 24 & 12 & 24 & 15 \\
\hline
\end{tabular}

Tabela 5 - Efeito dos níveis de substituição do farelo de soja (FS) da dieta por soja integral extrusada (SIE) sobre o número de leitões extratificados de acordo com a duração da diarréia durante os primeiros 14 dias após o desmame (experimentos 1 e 2 )

Table 5 - Effect of partial substitution of soybean meal (SM) by full-fat extruded soybean (ES) on the number of piglets extratified regarding the lenght of diarrhea during the first 14 postweaning days (experiments 1 and 2)

Níveis de substituição do FS por SIE, \% Duração da diarréia, dias

Substitution levels of SM by ES, \% Lenght of diarrhea, days

\begin{tabular}{|c|c|c|c|c|c|c|c|c|c|c|c|}
\hline & \multicolumn{5}{|c|}{$\begin{array}{c}\text { Experimento } 1 \\
\text { Experiment }\end{array}$} & \multicolumn{6}{|c|}{$\begin{array}{c}\text { Experimento } 2 \\
\text { Experiment } 2\end{array}$} \\
\hline & 1 & 2 & 3 & 4 & 5 & 1 & 2 & 3 & 4 & 5 & 6 \\
\hline 0 & 6 & 3 & 0 & 3 & 2 & 6 & 3 & 2 & 0 & 1 & 1 \\
\hline 20 & 8 & 5 & 0 & 1 & 0 & 6 & 4 & 0 & 1 & 0 & 0 \\
\hline 40 & 10 & 1 & 1 & 0 & 1 & 10 & 1 & 2 & 0 & 0 & 0 \\
\hline 60 & 6 & 3 & 1 & 2 & 0 & 8 & 5 & 0 & 2 & 0 & 0 \\
\hline
\end{tabular}

Tabela 6 - Efeito da substituição do farelo de soja (FS) pela soja integral extrusada (SIE) sobre o número total de leitões que apresentaram diarréia e número de leitões com diarréia extratificados de acordo com a duração da diarréia (dias) nos leitões abatidos para coleta de amostra do intestino (experimento 1)

Table 6 - Effect of partial substitution of soybean meal (SM) by full-fat extruded soybean (ES) on the number of piglets whith diarrhea and on the number of piglets extratified regarding the lenght of diarrhea in the piglets slaughtered to remove gut samples (experiment 1)

\begin{tabular}{|c|c|c|c|c|c|c|c|}
\hline \multirow[t]{2}{*}{$\begin{array}{l}\text { Níveis de substituição do FS por SIE, \% } \\
\text { Substitution levels of SM by ES , \% }\end{array}$} & \multirow[t]{2}{*}{$\begin{array}{c}\text { № total leitões } \\
\text { Total number } \\
\text { of piglets }\end{array}$} & \multirow[t]{2}{*}{$\begin{array}{l}\text { № leitões com diarréia } \\
\text { Number of piglets } \\
\text { with diarrhea }\end{array}$} & \multicolumn{5}{|c|}{$\begin{array}{c}\text { Duração da diarréia (dias) } \\
\text { Lenght of } \\
\text { diarrhea }(\text { days })\end{array}$} \\
\hline & & & 1 & 2 & 3 & 4 & 5 \\
\hline 0 & 8 & 6 & 3 & 0 & 1 & 0 & 2 \\
\hline 20 & 8 & 4 & 3 & 0 & 0 & 1 & 0 \\
\hline 40 & 8 & 2 & 0 & 1 & 0 & 1 & 0 \\
\hline 60 & 8 & 4 & 2 & 1 & 0 & 1 & 0 \\
\hline
\end{tabular}


750 Rev. bras. zootec.

Tabela 7 - Efeito dos níveis de substituição do farelo de soja (FS) por soja integral extrusada (SIE) sobre a altura da mucosa $(\mathrm{mm})$ de diferentes segmentos do intestino delgado dos leitões 14 dias após o desmame (experimento 1)

Table 7 - Effect of partial substitution of soybean meal (SM) by full-fat extruded soybean (ES) on the mucosa height (mm) of different sites of the small intestine of piglets, 14 days post-weaning (experiment 1)

\begin{tabular}{|c|c|c|c|c|}
\hline \multirow[t]{2}{*}{$\begin{array}{l}\text { Porção do intestino } \\
\text { Site in the intestine }\end{array}$} & \multicolumn{4}{|c|}{$\begin{array}{l}\text { Níveis de substituição do FS pela SIE, \% } \\
\text { Substitution levels of FS by SIE, \% }\end{array}$} \\
\hline & 0 & 20 & 40 & 60 \\
\hline $\begin{array}{l}\text { Duodeno }^{1} \\
\text { Duodenum }^{1}\end{array}$ & $883 \pm 104$ & $743 \pm 86$ & $796 \pm 67$ & $801 \pm 102$ \\
\hline $\begin{array}{l}\text { Jejuno fragmento } 1 \\
\text { Jejunum site } 1\end{array}$ & $773 \pm 87$ & $766 \pm 64$ & $758 \pm 56$ & $722 \pm 62$ \\
\hline $\begin{array}{l}\text { Jejuno fragmento } 2^{2} \\
\text { Jejunum site } 2^{2}\end{array}$ & $828 \pm 115$ & $727 \pm 64$ & $779 \pm 83$ & $679 \pm 74$ \\
\hline $\begin{array}{l}\text { Íleo } \\
\text { Ileum }\end{array}$ & $784 \pm 93$ & $719 \pm 72$ & $744 \pm 93$ & $729 \pm 52$ \\
\hline
\end{tabular}

1 Efeito quadrático $(\mathrm{P}<0,05) ;{ }^{2}$ Efeito linear $(\mathrm{P}<0,01)$.

1 Quadratic response $(P<.05))^{2}$ Linear response $(P<.01)$.

dias após o desmame, foi obtida parcialmente em função de aumento no consumo de alimento, mas também houve melhora na conversão alimentar. $\mathrm{O}$ baixo ganho de peso em todos os tratamentos nos primeiros 14 dias após o desmame neste experimento parece ter sido causado, em parte, pelo baixo consumo de alimento e pela conversão alimentar insuficiente, o que pode ter sido provocado pelo baixo nível de soro de leite em pó incluído na dieta (14\%), pela alta incidência de diarréia e outros problemas como doença do edema. O desaparecimento do efeito significativo das dietas experimentais sobre o GPD, quando se avalia o período total da creche, provavelmente ocorreu em função do baixo ganho de peso ocorrido em todos os tratamentos, no período de fornecimento das mesmas (0 a 14 dias), e do alto ganho de peso em todos os tratamentos no período seguinte (15 a 35 dias), o que diluiu a diferença obtida na fase anterior.

\section{Experimento 2}

Foi observado efeito quadrático dos níveis de substituição do FS pela SIE nos dois períodos estudados, bem como no período total, em que os melhores resultados de GPD, CRD, CA, peso médio aos 14 (PM14), 28 (PM28) e 35 dias do experimento (PM35) foram obtidos nos níveis de 20 e $40 \%$ de substituição do FS pela SIE (Tabela 8): GPD014 $(\mathrm{P}<0,002, \mathrm{y}=134+$ $\left.2,36 \mathrm{x}-0,044 \mathrm{x}^{2}\right), \mathrm{CRD} 014(\mathrm{P}<0,07, \mathrm{y}=255+1,24 \mathrm{x}-$ $\left.0,025 \mathrm{x}^{2}\right)$, CA014 $(\mathrm{P}<0,0007, \mathrm{y}=1,94-0,02 \mathrm{x}+$ $\left.0,00037 \mathrm{x}^{2}\right)$, GPD1535 $(\mathrm{P}<0,03, \mathrm{y}=533+4,84 \mathrm{x}-$ $\left.0,076 \mathrm{x}^{2}\right)$, CRD1535 $(\mathrm{P}<0,03, \mathrm{y}=866+7,47 \mathrm{x}-$ $\left.0,126 \mathrm{x}^{2}\right), \operatorname{GPD} 035\left(\mathrm{P}<0,01, \mathrm{y}=373+3,85 \mathrm{x}-0,063 \mathrm{x}^{2}\right)$,
CRD035 $\left(\mathrm{P}<0,02, \mathrm{y}=622+4,98 \mathrm{x}-0,086 \mathrm{x}^{2}\right), \mathrm{PM} 14$ $\left(\mathrm{P}<0,07, \mathrm{y}=9,18+0,046 \mathrm{x}-0,0008 \mathrm{x}^{2}\right), \mathrm{PM} 28(\mathrm{P}<0,04$, $\left.\mathrm{y}=16,02+0,098 \mathrm{x}-0,0017 \mathrm{x}^{2}\right)$, PM35 $(\mathrm{P}<0,02$, $\left.y=20,36+0,147 x-0,0024 x^{2}\right)$. A única exceção foi a CA do período de 15 a 35 dias, a qual reduziu linearmente $(\mathrm{P}<0,10, \mathrm{y}=1,63-0,00097 \mathrm{x})$ com o aumento da inclusão da SIE na dieta da fase anterior.

Não houve efeito dos tratamentos sobre o NLD (Tabela 4) nem sobre o NLDD (Tabela 5).

O aumento obtido no GPD com a substituição de até $40 \%$ do FS pela SIE foi causado por aumento do consumo de alimento. A explicação mais provável para o baixo desempenho dos leitões do maior nível de substituição (60\%) foi a ocorrência de diarréia em no mínimo dois leitões a mais que nos outros tratamentos. O valor máximo estimado de GPD, por meio da derivação da equação quadrática, foi de $26,82 \%$ de substituição do FS, para o período de 0 a 14 dias pós-desmame.

Os leitões alimentados com as dietas em que a SIE substituiu parcialmente o FS apresentaram melhor desempenho no período de fornecimento das dietas. Uma das causas deste melhor desempenho foi o aumento do consumo de alimento. No entanto, nem sempre este resultado se refletiu em melhoria significativa do desempenho em toda a fase de creche. A melhora da conversão alimentar obtida nos experimentos 1 e 2 não pode ser atribuída ao maior conteúdo de EM da SIE em relação ao FS, uma vez que as dietas foram isocalóricas, mas pode ter sido causada de melhor aproveitamento dos aminoácidos da SIE. Foi observado que a extrusão dos produtos da soja 
BERTOL et al.

Tabela 8 - Efeito da substituição parcial do farelo de soja (FS) por soja integral extrusada (SIE) sobre o desempenho de leitões desmamados aos 21 dias de idade (experimento 2)

Table 8 - Effect of partial substitution of soybean meal (SM) by full-fat extruded soybean (ES) on the performance of piglets weaned at 21 days of age (experiment 2)

\begin{tabular}{|c|c|c|c|c|}
\hline & \multicolumn{4}{|c|}{$\begin{array}{l}\text { Níveis de substituição do FS pela SIE, \% } \\
\text { Substitution levels of FS by SIE, \% }\end{array}$} \\
\hline & 0 & 20 & 40 & 60 \\
\hline & \multicolumn{4}{|c|}{$\begin{array}{l}0 \text { a } 14 \text { dias } \\
0 \text { to } 14 \text { days }\end{array}$} \\
\hline $\begin{array}{l}\text { Peso médio inicial, } \mathrm{kg} \\
\text { Initial mean weight, } \mathrm{kg}\end{array}$ & $7,29 \pm 0,89$ & $7,51 \pm 0,83$ & $7,42 \pm 1,20$ & $7,29 \pm 0,99$ \\
\hline $\begin{array}{l}\text { Ganho peso diário }{ }^{1}, \mathrm{~g} \\
\text { Daily weight } \text { gain }^{1}, g\end{array}$ & $133 \pm 31$ & $163 \pm 44$ & $159 \pm 28$ & $119 \pm 17$ \\
\hline $\begin{array}{l}\text { Consumo ração diário }{ }^{2}, \mathrm{~g} \\
\text { Daily feed intake } e^{2}, g\end{array}$ & $256 \pm 47$ & $268 \pm 42$ & $268 \pm 17$ & $240 \pm 18$ \\
\hline $\begin{array}{l}\text { Conversão alimentar } \\
\text { Feed:gain ratio }\end{array}$ & $1,94 \pm 0,15$ & $1,70 \pm 0,23$ & $1,72 \pm 0,22$ & $2,06 \pm 0,29$ \\
\hline \multirow[t]{2}{*}{$\begin{array}{l}\text { Peso médio aos } 14 \text { dias }^{2}, \mathrm{~kg} \\
\text { Average weight at } 14 \text { days }{ }^{2}, \mathrm{~kg}\end{array}$} & $9,16 \pm 1,21$ & $9,79 \pm 0,96$ & $9,65 \pm 1,12$ & $8,95 \pm 0,97$ \\
\hline & \multicolumn{4}{|c|}{$\begin{array}{l}15 \text { a } 35 \text { dias } \\
15 \text { to } 35 \text { days }\end{array}$} \\
\hline $\begin{array}{l}\text { Ganho peso diário }{ }^{3}, \mathrm{~g} \\
\text { Daily weight gain }{ }^{3}, g\end{array}$ & $531 \pm 59$ & $603 \pm 68$ & $600 \pm 100$ & $549 \pm 93$ \\
\hline $\begin{array}{l}\text { Consumo ração diário }{ }^{3}, \mathrm{~g} \\
\text { Daily feed intake }{ }^{3}, g\end{array}$ & $862 \pm 87$ & $978 \pm 114$ & $950 \pm 160$ & $864 \pm 150$ \\
\hline $\begin{array}{l}\text { Conversão alimentar } \\
\text { Feed:gain ratio }\end{array}$ & $1,63 \pm 0,06$ & $1,62 \pm 0,10$ & $1,58 \pm 0,04$ & $1,57 \pm 0,07$ \\
\hline \multirow[t]{2}{*}{$\begin{array}{l}\text { Peso médio aos } 28 \text { dias }^{3}, \mathrm{~kg} \\
\text { Average weight at } 28^{3}, \mathrm{~kg}^{2}\end{array}$} & $16,02 \pm 1,61$ & $17,28 \pm 1,21$ & $17,23 \pm 2,23$ & $15,78 \pm 2,17$ \\
\hline & \multicolumn{4}{|c|}{$\begin{array}{l}0 \text { a } 35 \text { dias } \\
0 \text { to } 35 \text { days }\end{array}$} \\
\hline $\begin{array}{l}\text { Ganho peso diário }{ }^{1}, \mathrm{~g} \\
\text { Daily weight gain }{ }^{1}, g\end{array}$ & $372 \pm 39$ & $427 \pm 49$ & $423 \pm 62$ & $377 \pm 56$ \\
\hline $\begin{array}{l}\text { Consumo ração diário }{ }^{3}, \mathrm{~g} \\
\text { Daily feed intake }{ }^{3}, g\end{array}$ & $619 \pm 53$ & $694 \pm 69$ & $677 \pm 94$ & $614 \pm 94$ \\
\hline $\begin{array}{l}\text { Conversão alimentar } \\
\text { Feed:gain ratio }\end{array}$ & $1,67 \pm 0,06$ & $1,63 \pm 0,09$ & $1,60 \pm 0,05$ & $1,63 \pm 0,06$ \\
\hline $\begin{array}{l}\text { Peso médio aos } 35 \text { dias }^{1}, \mathrm{~kg} \\
\text { Average weight at } 35 \text { days }^{1}, \mathrm{~kg}\end{array}$ & $20,32 \pm 1,76$ & $22,46 \pm 1,66$ & $22,24 \pm 2,68$ & $20,48 \pm 2,78$ \\
\hline
\end{tabular}

melhora a digestibilidade do $\mathrm{N}$, por intermédio da desnaturação da matriz da protéica (FRIESEN et al., 1992; PARTRIDGE e GILL, 1993).

Os valores de urease $(0,03)$ e solubilidade protéica em $\mathrm{KOH}(83,26 \%)$ indicam que o processamento da SIE utilizada em ambos os experimentos foi adequado, o que contribuiu para o bom desempenho apresentado pelos leitões. A utilização de SIE com valores de atividade ureática de 0,08 e 0,47 e de solubilidade protéica em $\mathrm{KOH}$ de 70,74 e 54,85\%, respectivamente, proporcionaram desempenho semelhante ao FS no primeiro caso (MOREIRA et al., 1993) e redução do desempenho no segundo caso (MOREIRA et al., 1994), com a substituição parcial do FS por SIE na dieta de leitões entre 21 e 42 dias de idade. Isto indica como a variabilidade no processamento pode provocar diferentes respostas no desempenho dos leitões alimentados com dietas contendo subprodutos da soja. Em função disto, os parâmetros de processamento devem ser monitorados de forma a garantir que sejam adequados para reduzir os fatores antinutricionais a níveis aceitáveis (VANDERGRIFT, 1985) e garantir bom desempenho.

A idade dos leitões e a composição da dieta são dois fatores que influenciam a estrutura da mucosa intestinal dos leitões em termos de altura das vilosidades e profundidade da cripta (MILLER et al., 1984; LI et al., 1990a). Em geral, a AMM foi superior 
nos animais que receberam a dieta em que o FS foi a única fonte de proteína, em todos os segmentos do intestino avaliados. É provável que isto tenha sido causado por uma hiperplasia da cripta, em consequência de aumento na taxa de mitose dos enterócitos, em resposta aos fatores antigênicos presentes no FS, de acordo com relatos de outros autores (DUNSFORD et al. 1989 e LI et al. 1991b). FRIESEN et al. (1993) observaram que a extrusão úmida reduz a concentração dos inibidores da tripsina e as propriedades antigênicas dos subprodutos da soja, resultando em melhor digestibilidade e redução do potencial para resposta imune às proteínas da soja. A diminuição do potencial para resposta imune se dá por intermédio da desnaturação das proteínas biologicamente ativas da soja (glicinina e $\beta$-conglicinina). LI et al. (1991b) observaram menor altura das vilosidades e maior profundidade da cripta no intestino de leitões alimentados com dietas baseadas em FS, comparados àqueles alimentados com dietas contendo proteína do leite, proteína concentrada de soja ou proteína concentrada de soja extrusada. DUNSFORD et al. (1989) observaram menor altura das vilosidades e maior profundidade da lâmina própria em leitões alimentados com dietas contendo FS como principal fonte de proteína, em comparação com aqueles que receberam dietas contendo caseína. Há evidências de que a resposta imune específica à proteína da soja, provocada após a ingestão oral desta proteína, pode estar envolvida nos distúrbios digestivos que ocorrem no desmame (HANKINS et al., 1992).

A redução da $\mathrm{AMM}$ nos diversos segmentos do intestino delgado, nos tratamentos em que a SIE substituiu parcialmente o FS, indica que o processamento para obtenção da SIE utilizada nestes experimentos provocou a desnaturação das proteínas antigênicas neste produto.

\section{Conclusões}

A substituição parcial do farelo de soja pela soja integral extrusada na dieta de leitões desmamados aos 21 dias de idade melhora o desempenho dos leitões na fase inicial após o desmame.

No experimento 1 , não foi possível determinar qual o valor máximo de substituição do farelo de soja pelo pela soja integral extrusada, uma vez que houve resposta linear no GPD até o nível de $60 \%$ de substituição. No entanto, no experimento 2, o melhor resultado de ganho de peso, estimado por intermédio da derivação da equação quadrática, foi de $26,82 \%$ de substituição do farelo de soja pela soja integral extrusada, para o período de 0 a 14 dias após o desmame realizado aos 21 dias de idade.

Os efeitos residuais da substituição do farelo de soja pela soja integral extrusada na dieta pré-inicial sobre o desempenho no período total de creche não foram consistentes.

\section{Referências Bibliográficas}

BERTOL, T.M., LUDKE, J.V. 1999. Determinação dos valores de energia e do balanço de nitrogênio de alguns alimentos para leitões na fase inicial. Rev. bras. zootec., 28(6):1296-1304.

DUNSFORD, B.R., KNABE, D.A., HAENSLY, W.E. 1989. Effect of dietary soybean meal on the microscopic anatomy of the small intestine in the early-weaned pig. J. Anim. Sci., 67(7):1855-1863.

CENTRO NACIONAL DE PESQUISA EM SUÍNOS E AVES EMBRAPA. 1991. Tabela de composição química e valores energéticos de alimentos para suínos e aves. 3.ed. Concórdia. 97p. (EMBRAPA-CNPSA. Documentos, 19).

FRIESEN, K.G., NELSSEN, J.L., BEHNKE, K.C. 1992. Effect of extrusion parameters. Feed International, 13(9):50-55.

FRIESEN, K.G., NELSSEN, J.L., GOODBAND, R.D. et al. 1993. The effect of moist extrusion of soy products on growth performance and nutrient utilization in the earlyweaned pig. J. Anim. Sci., 71(8):2099-2109.

HANKINS, C.C., NOLAND, P.R., BURKS JR., A.W. et al. 1992. Effect of soy protein ingestion on total and specific immunoglobulin $\mathrm{G}$ concentrations in neonatal porcine serum measured by enzyme-linked immunosorbent assay. J. Anim. Sci., 70:3096-3101.

HANCOCK, J.D., PEO JR., E.R., LEWIS, A.J. et al. 1990. Effects of ethanol extraction and duration of heat treatment of soybean flakes on the utilization of soybean protein by growing rats and pigs. J. Anim. Sci., 68(10):3233-3243.

LI, D.F., NELSSEN, J.L., REDDY, P.G. et al. 1990. Transient hypersensivity to soybean meal in the early-weaned pig. J. Anim. Sci., 68(6):1790-1799.

LI, D.F., NELSSEN, J.L., REDDY, P.G. et al. 1991a. Interrelationship between hypersensivity to soybean proteins and growth performance in early-weaned pigs. J. Anim. Sci., 69(10):4062-4069.

LI, D.F., NELSSEN, J.L., REDDY, P.G. et al. 1991b. Measuring suitability of soybean products for early-weaned pigs with immunological criteria. J. Anim. Sci., 69(8):3299-3307.

LINDEMAN, M.D., CORNELIUS, S.G., EL KANDELGY, S.M. et al. 1986. Effect of age, weaning and diet on digestive enzyme levels in the piglet. J. Anim. Sci., 62:1298-1307.

LUNA, L.G. 1968. Manual of histologic staining methods of the Armed Forces Institute of Pathology. 3.ed. New York: McGraw-Will. 258p.

McCRACKEN, K.J., KELLY, D. 1993. Development of digestive function and nutrition/disease interactions in the weaned pig.

Recebido em: 11/09/99 Aceito em: 18/01/01 